SUPPLEMENTARY MATERIALS: NMR Spectra and HPLC Analysis

for the

communication

entitled

\title{
De Novo Chiral Amino Alcohols in Catalyzing Asymmetric Additions to Aryl Aldehydes.
}

authored by

Jian Huang, ${ }^{a}$ James C. Ianni, ${ }^{b}$ Jennifer E. Antoline, ${ }^{a}$ Richard P. Hsung*c and Marisa C. Kozlowski*b

${ }^{a}$ Department of Chemistry, University of Minnesota, Minneapolis, MN 55455

${ }^{b}$ Department of Chemistry, Roy and Diana Vagelos Laboratories, University of Pennsylvania, Philadelphia, PA 19104

' Division of Pharmaceutical Sciences and Department of Chemistry, University of Wisconsin, Madison, WI 53705 


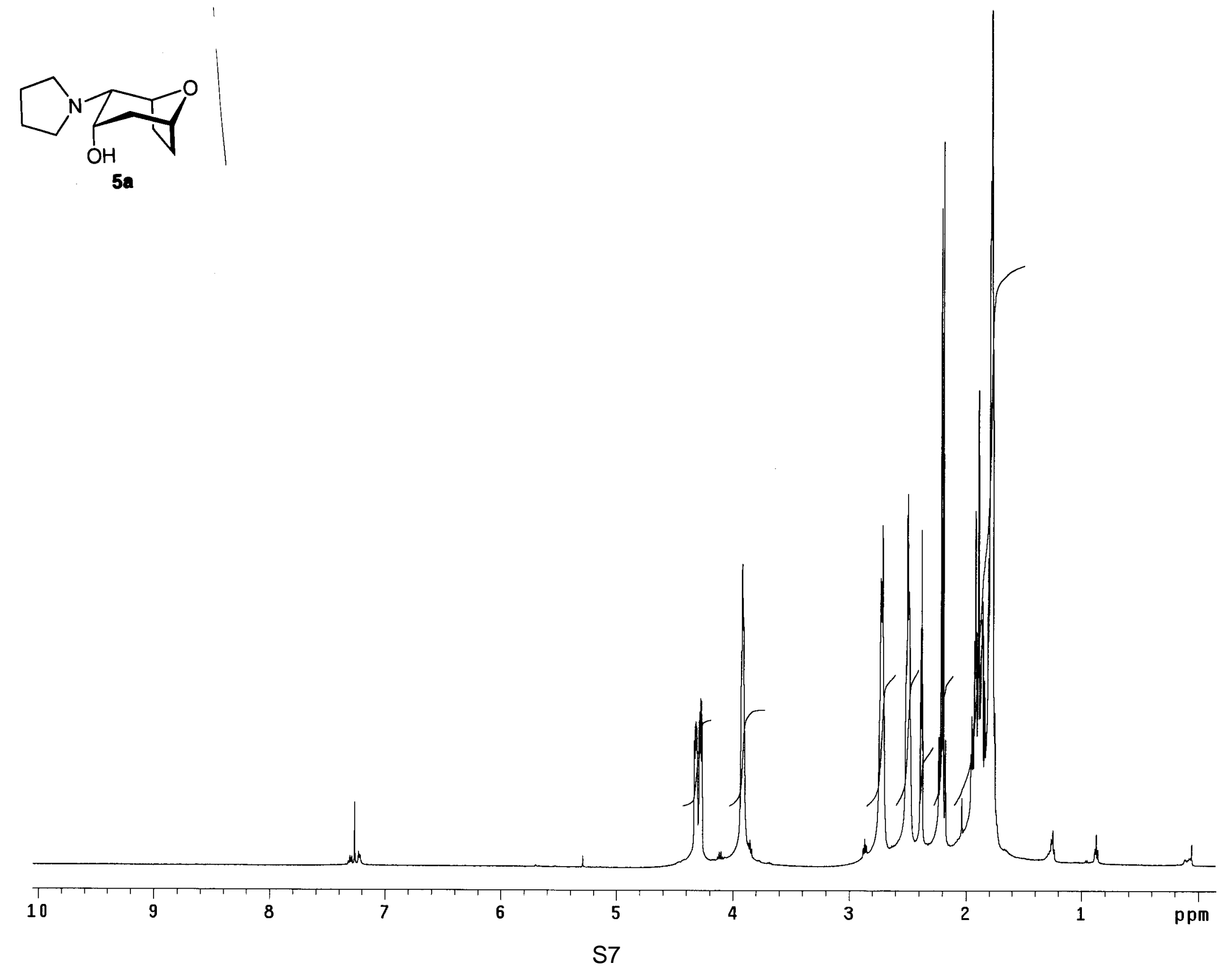




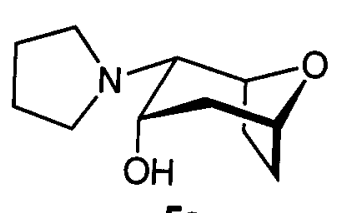

$5 a$

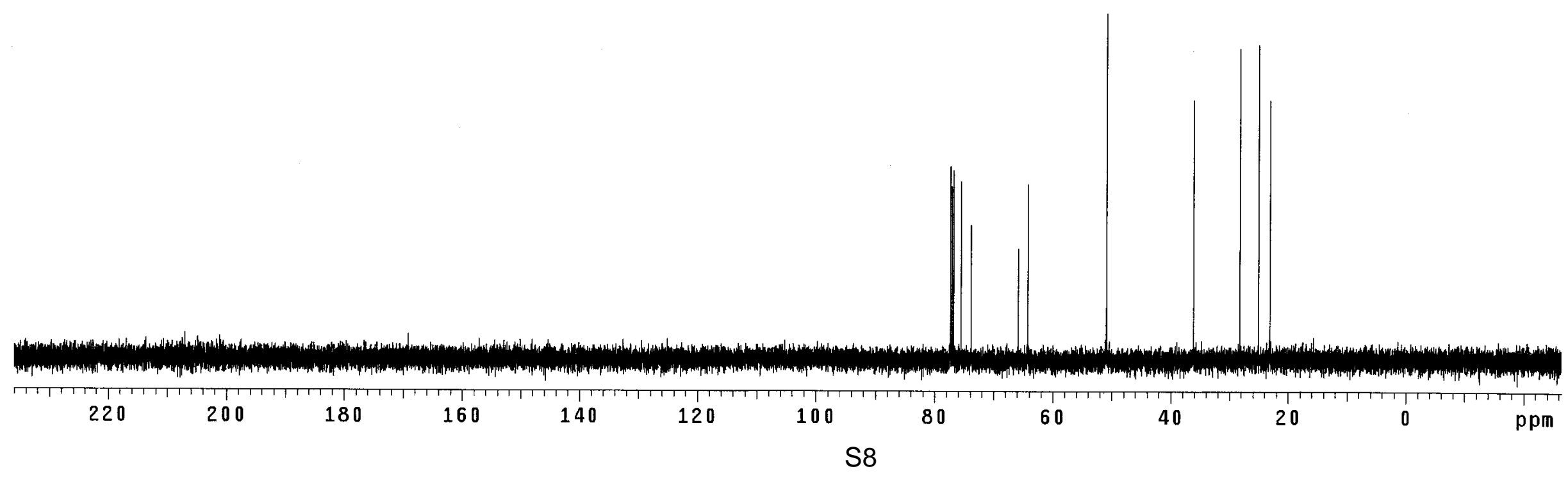




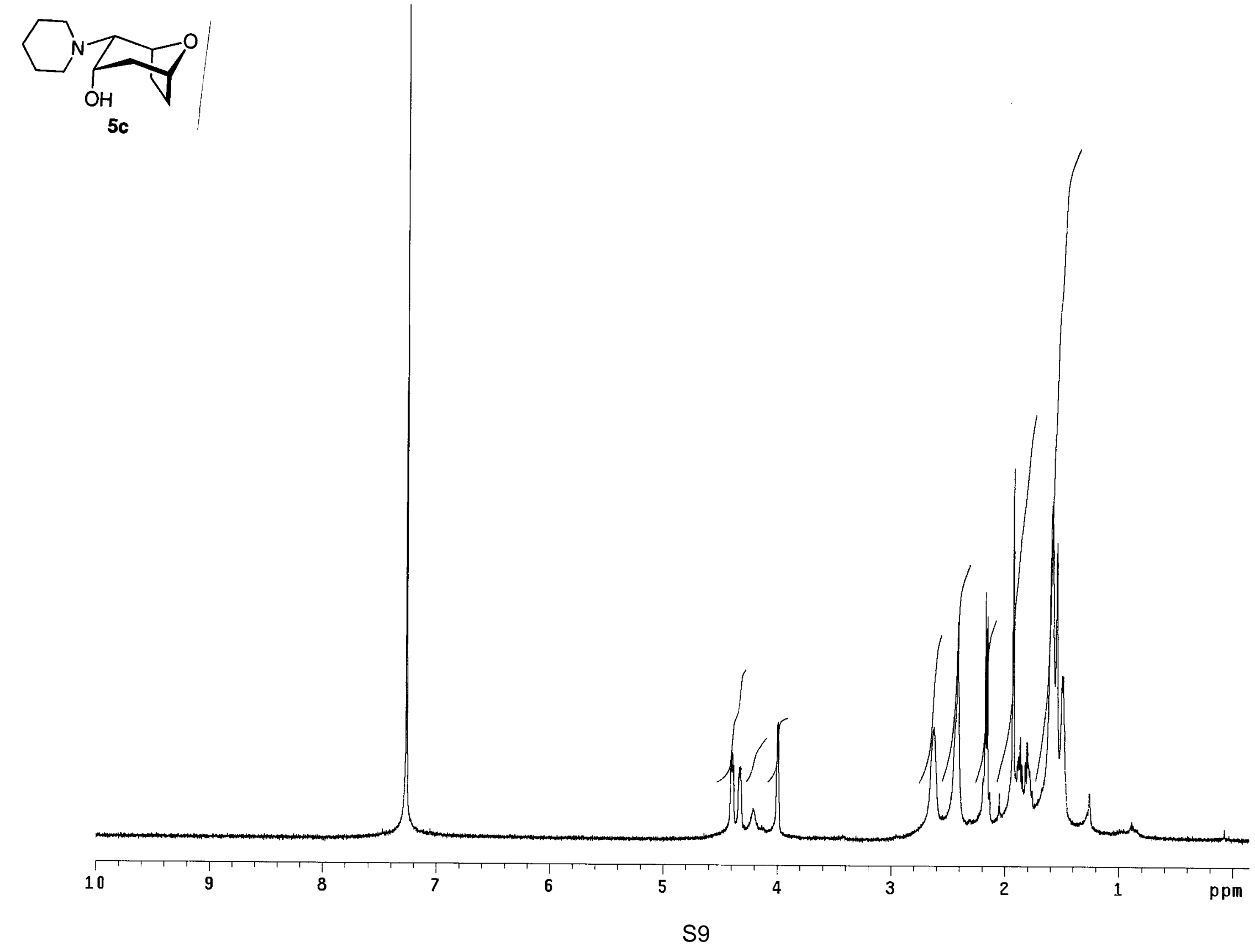




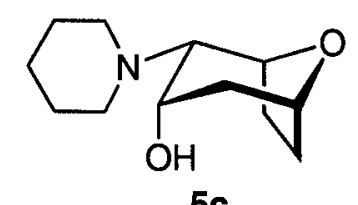

$5 c$

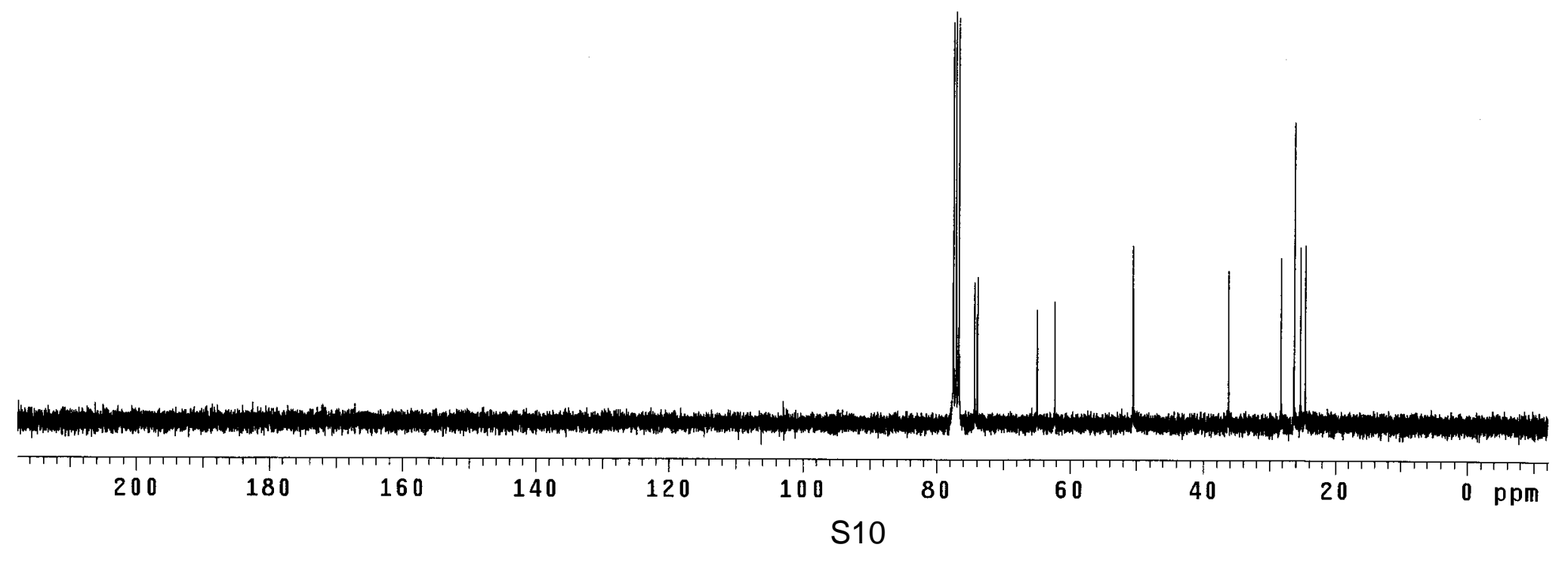




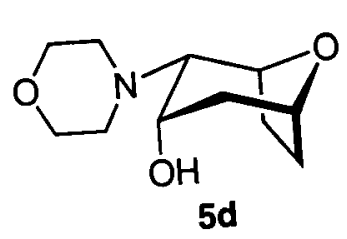

$5 d$

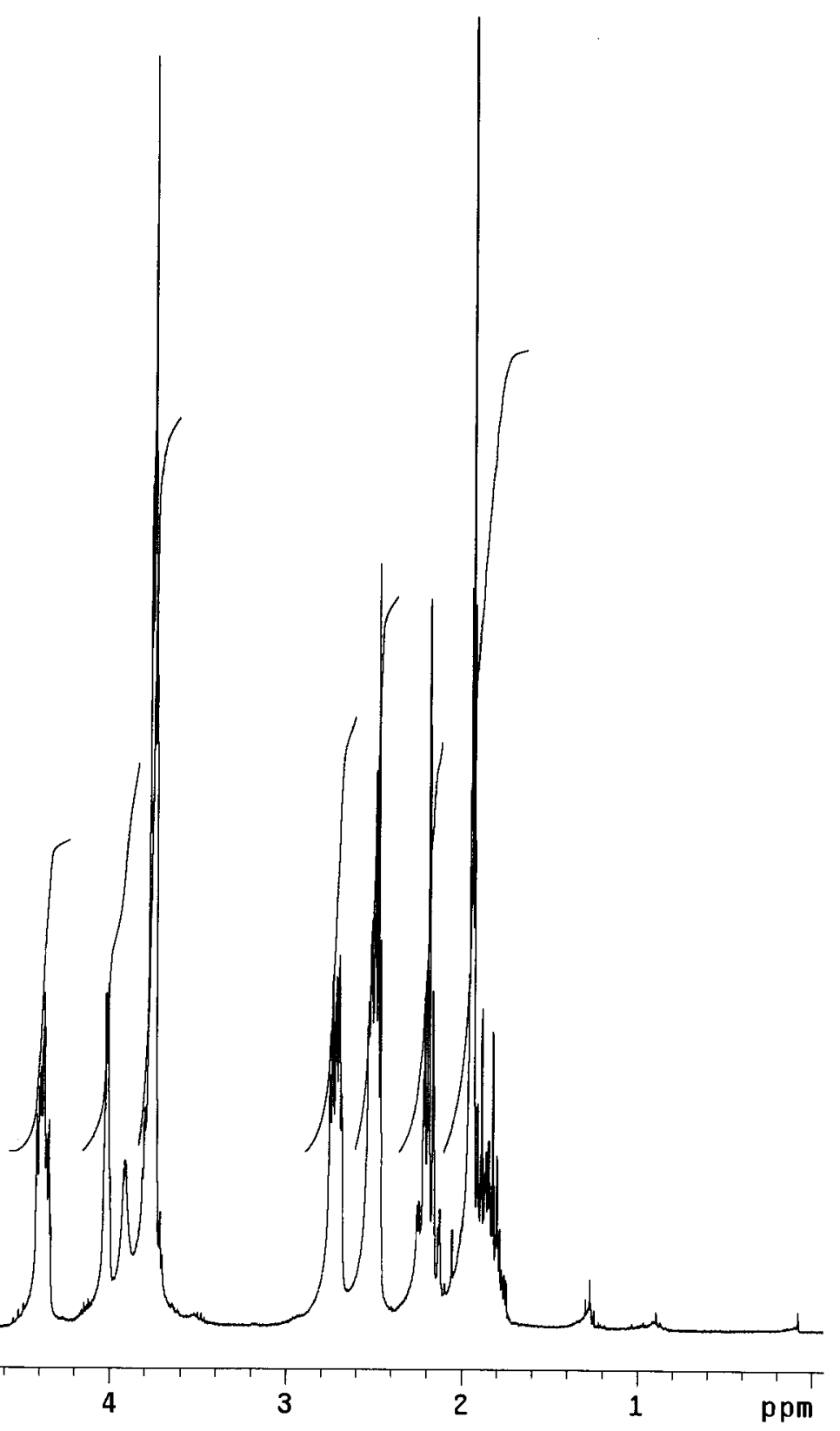

S11 


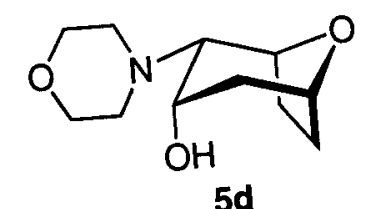

$5 d$

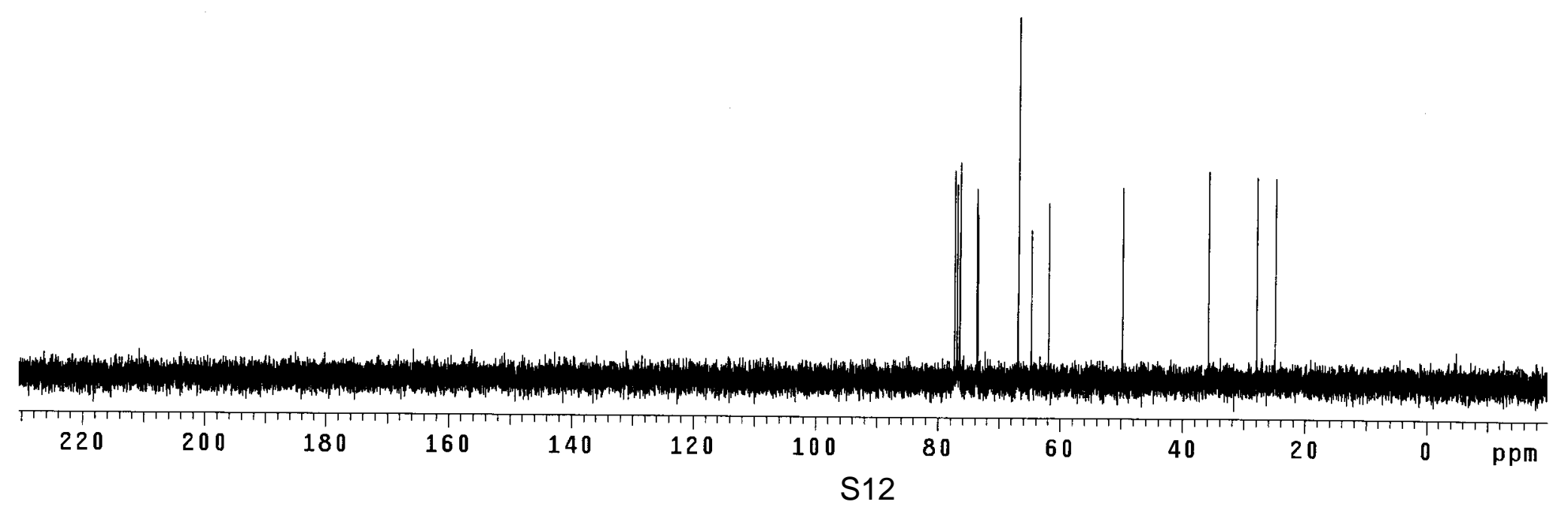


0

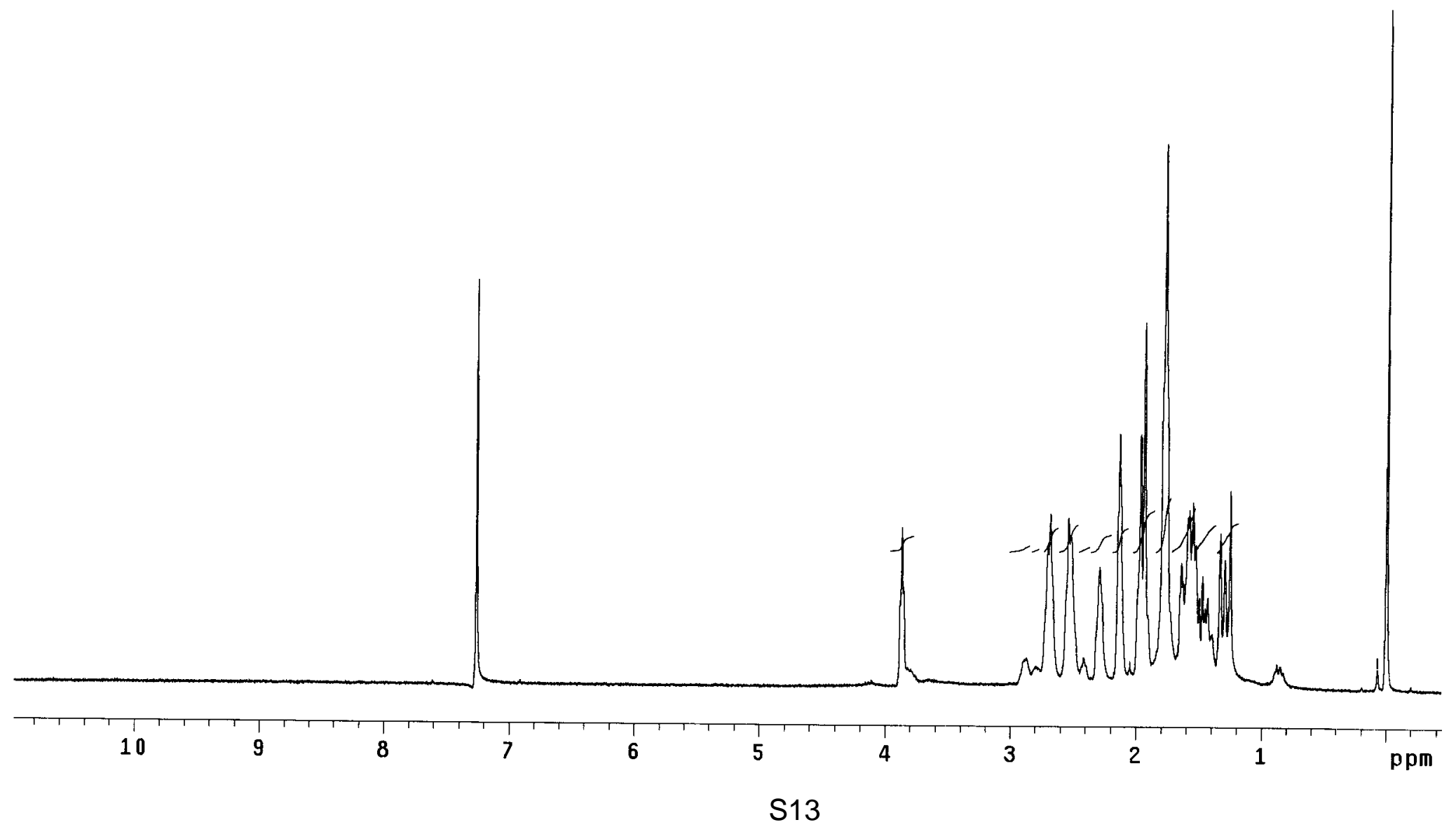



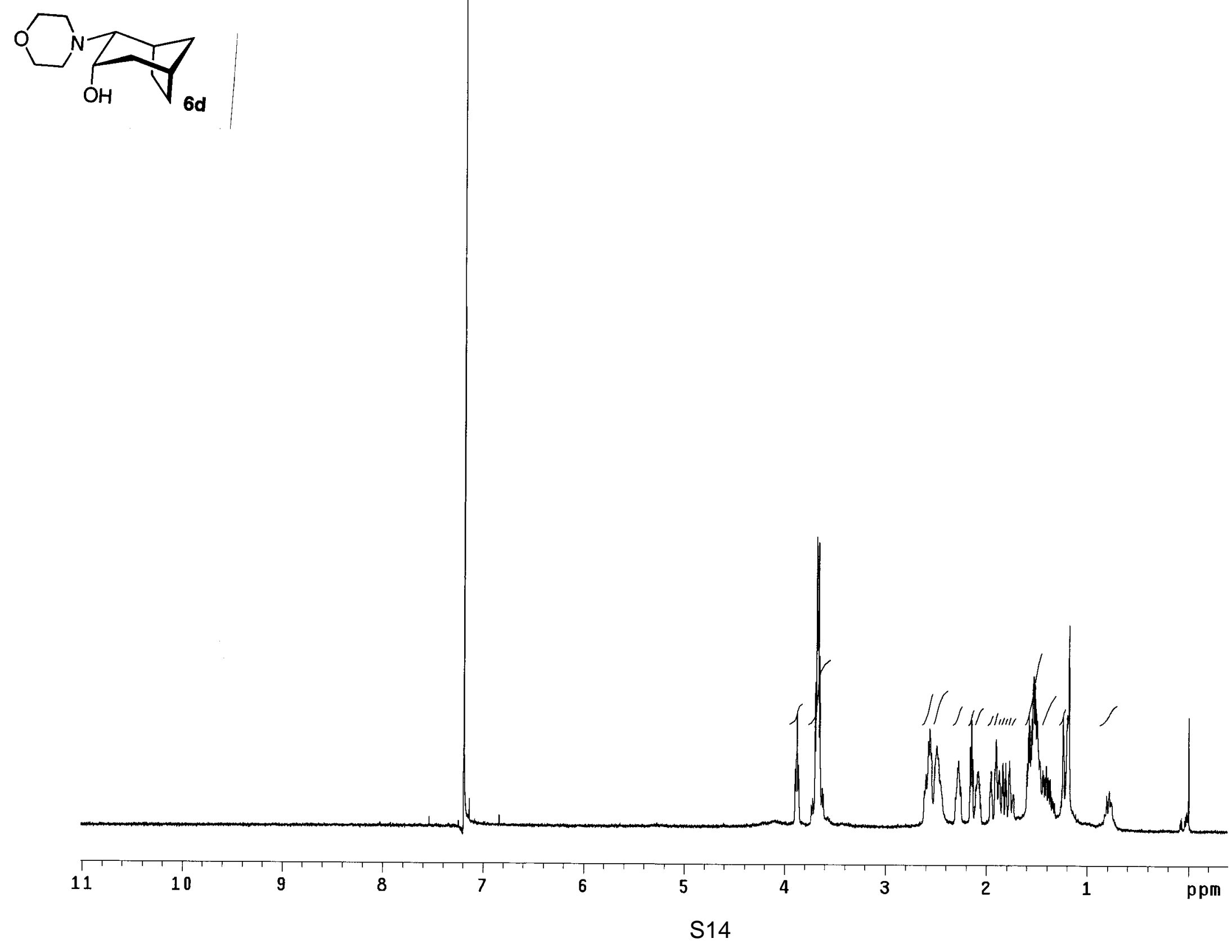

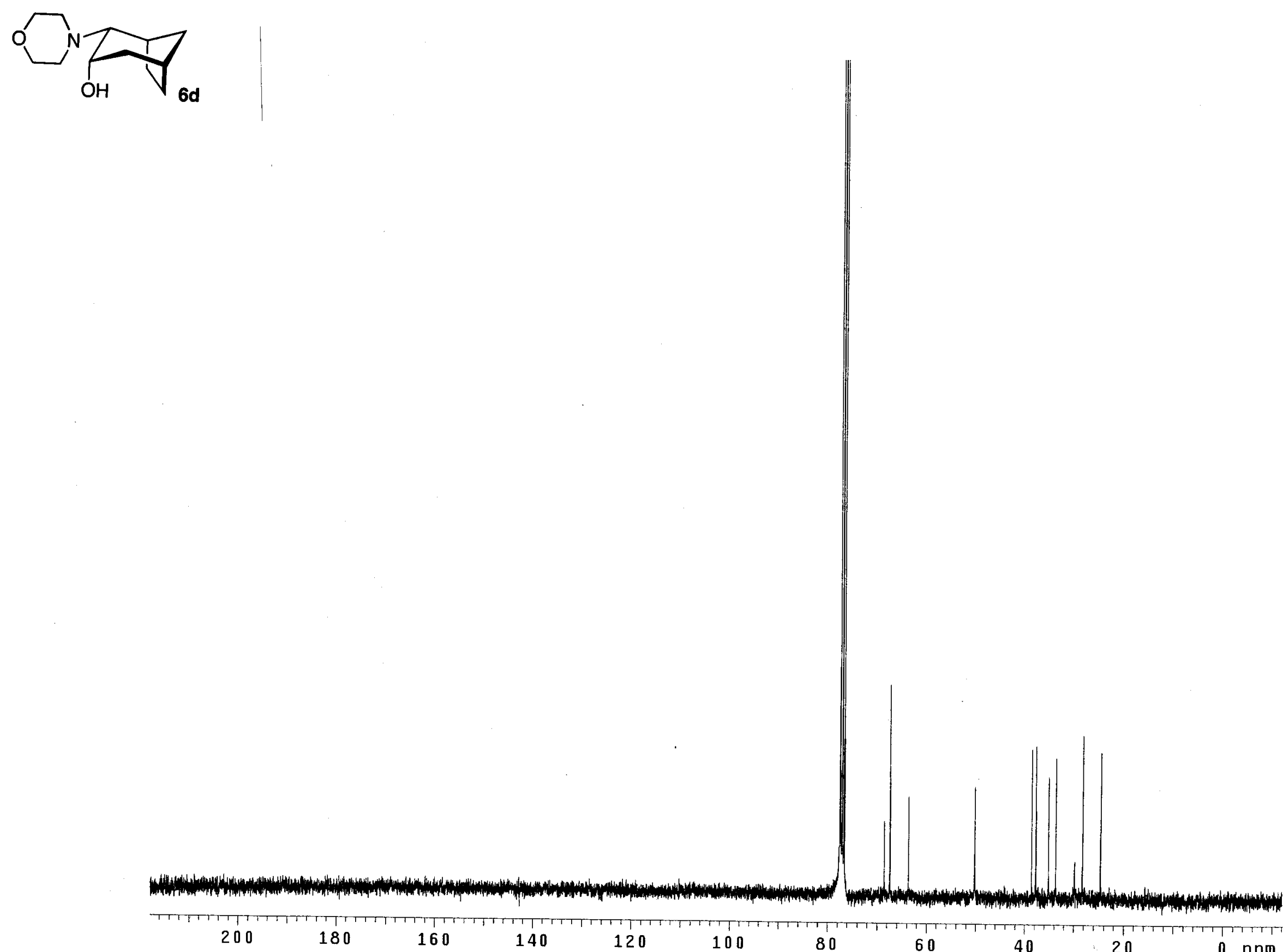
S15 

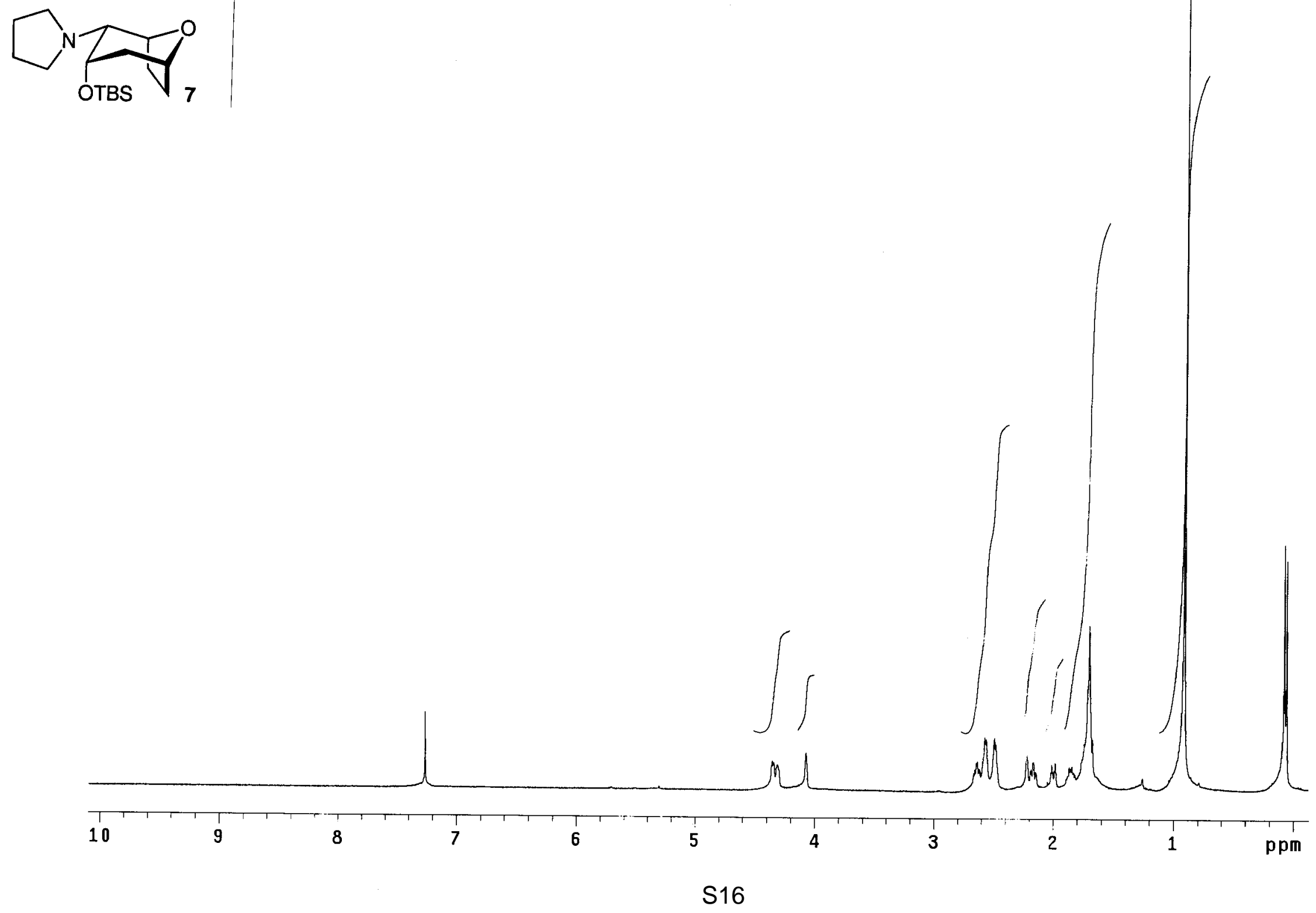

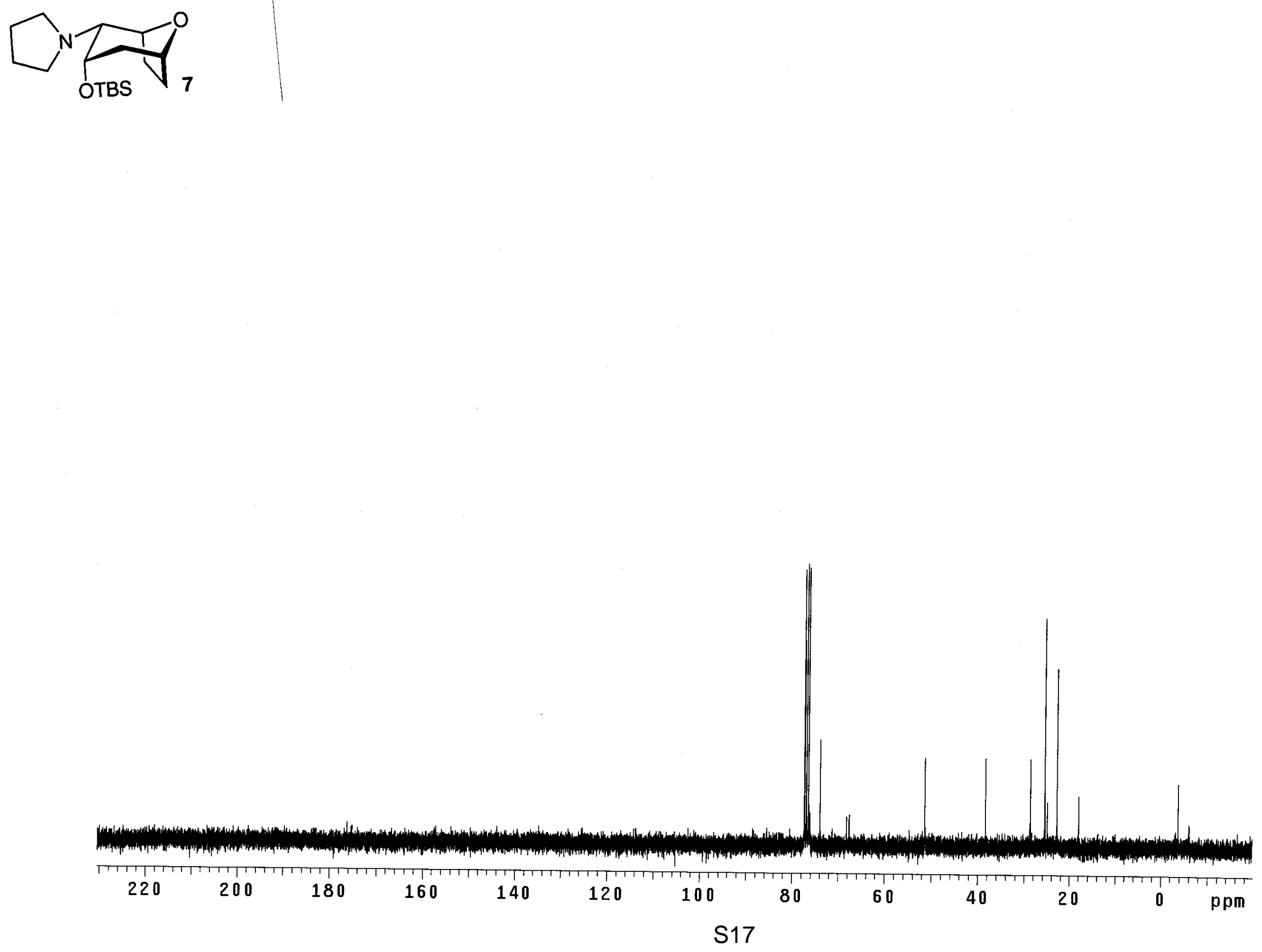

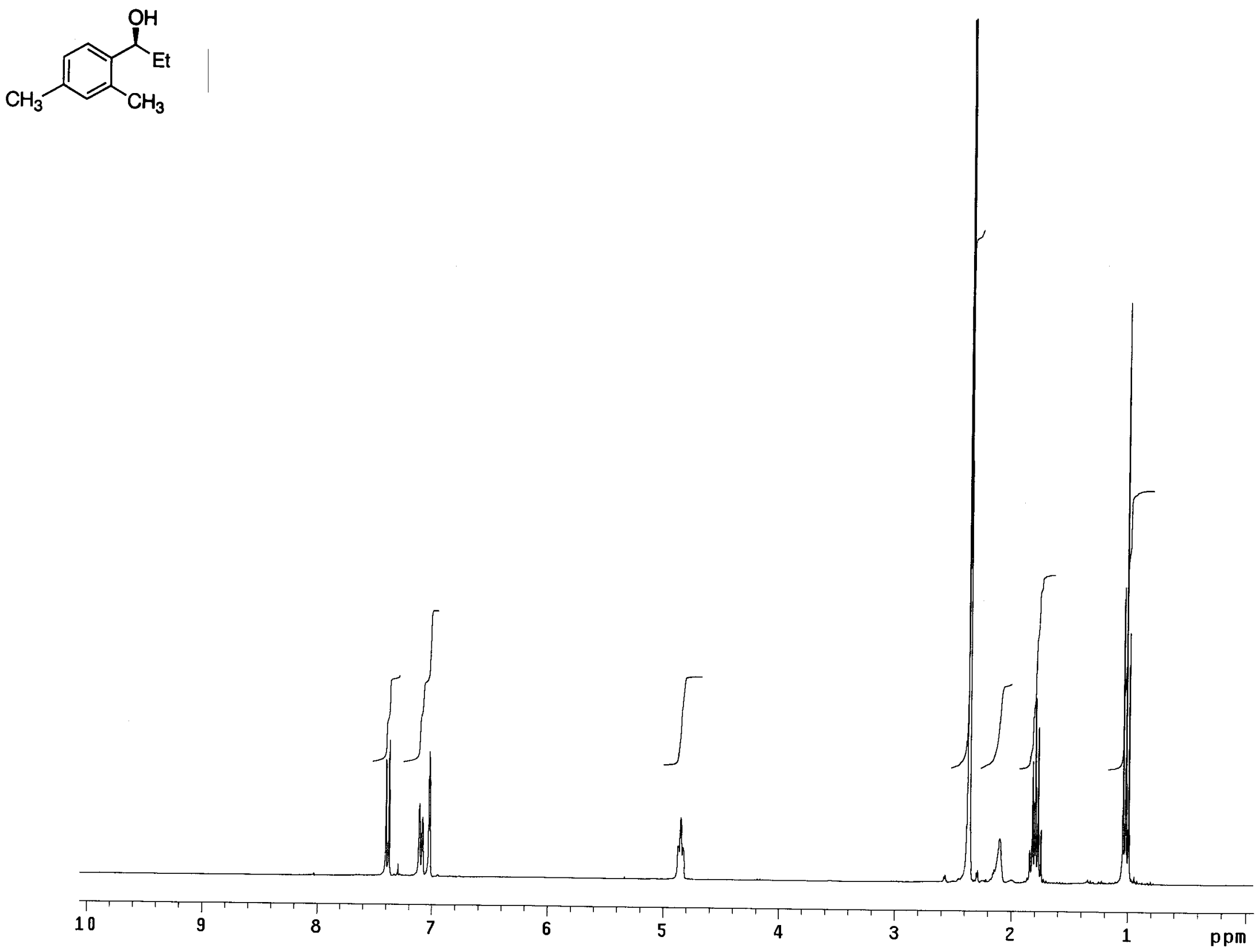

S18 
<smiles>CCC(O)c1ccc(C)cc1C</smiles>

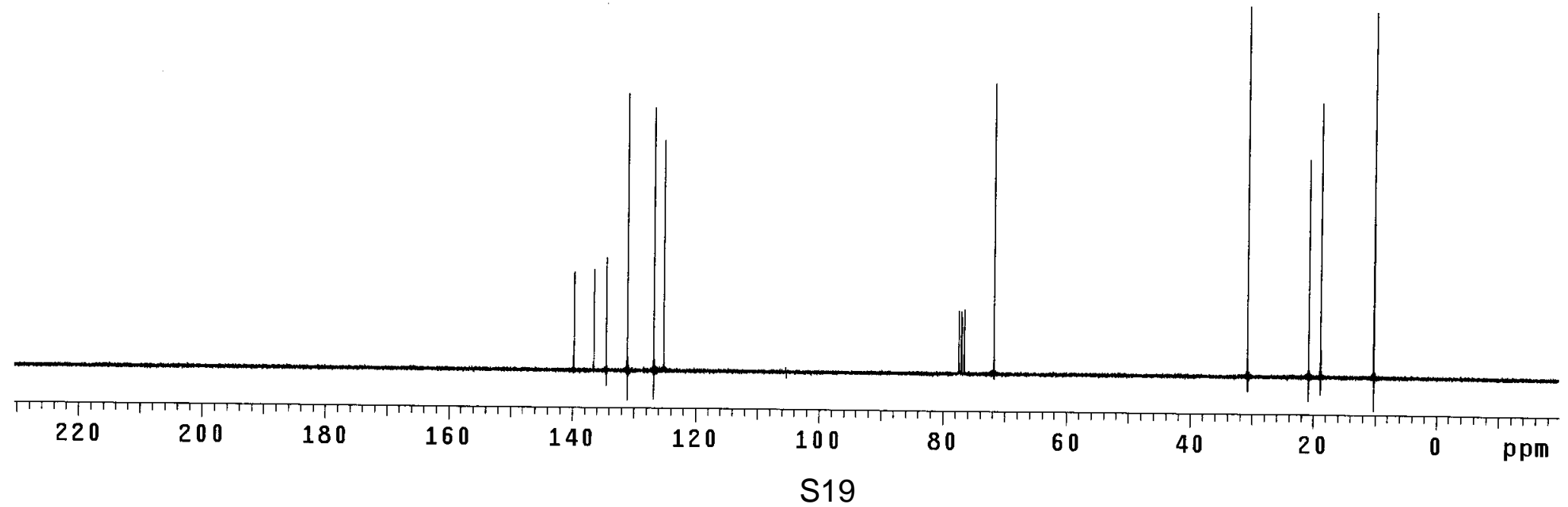


Print of window 38: Current Chromatogram(s)

$2.5 \mathrm{iproh}-1 \mathrm{ml} / \mathrm{min}$

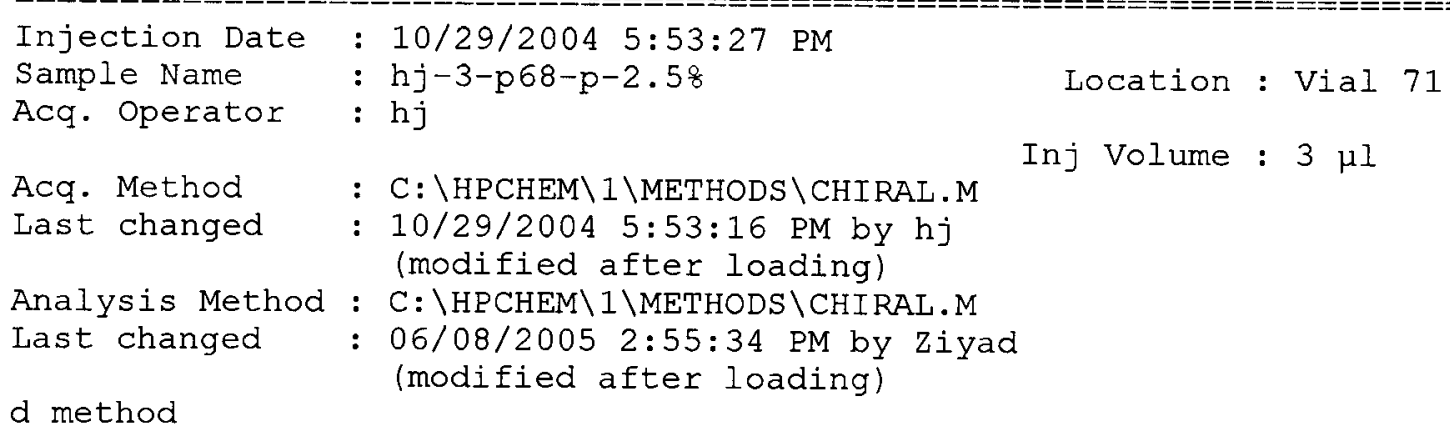<smiles>CCC(O)c1ccccc1</smiles>

Current Chromatogram(s)

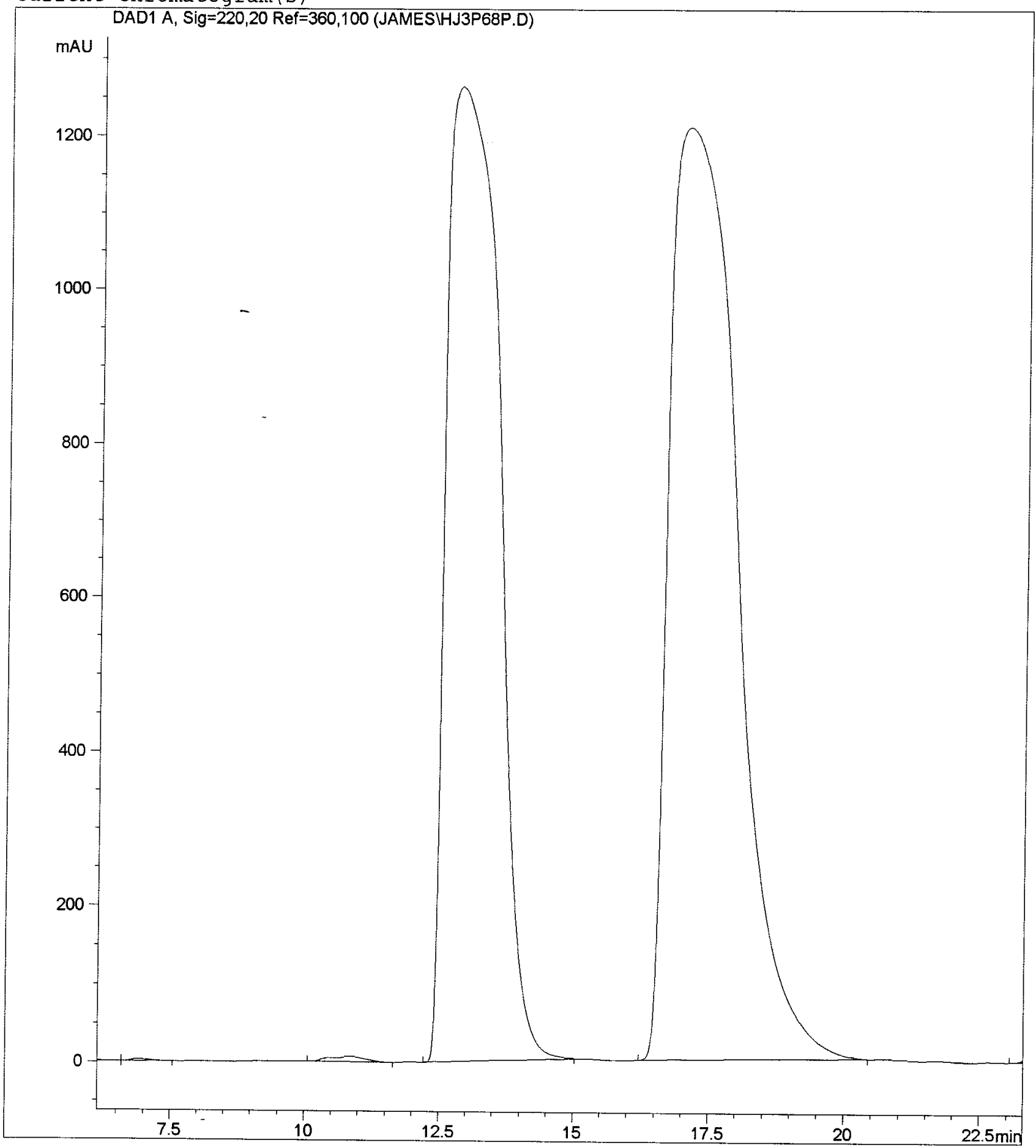


Print of window 38: Current Chromatogram(s) iproh $2.5 \% 1 \mathrm{ml} / \mathrm{min}$

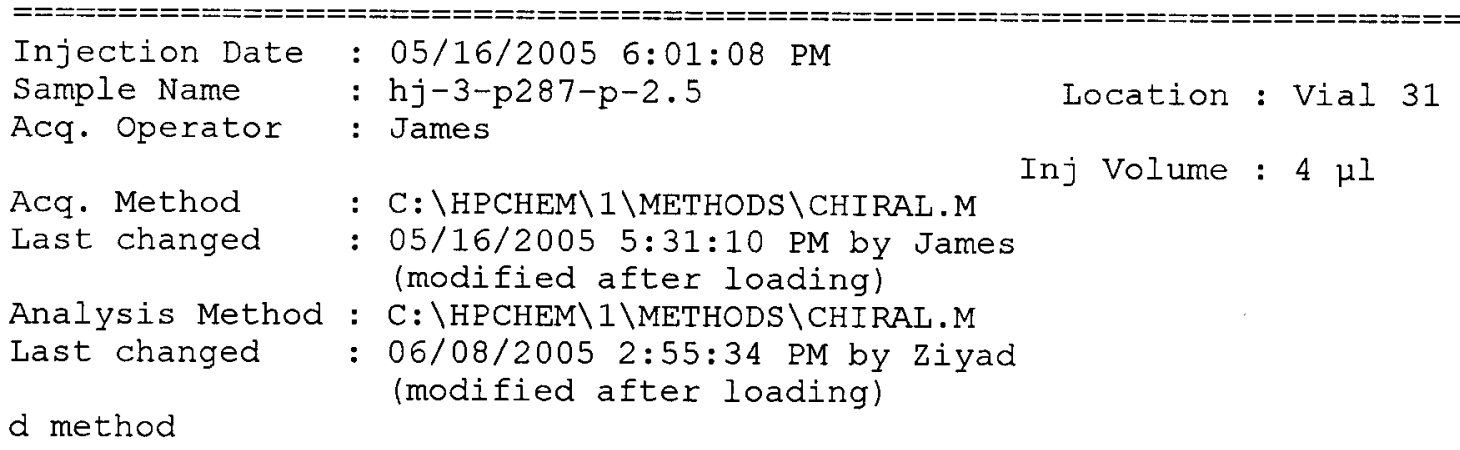

\section{Current Chromatogram(s)}

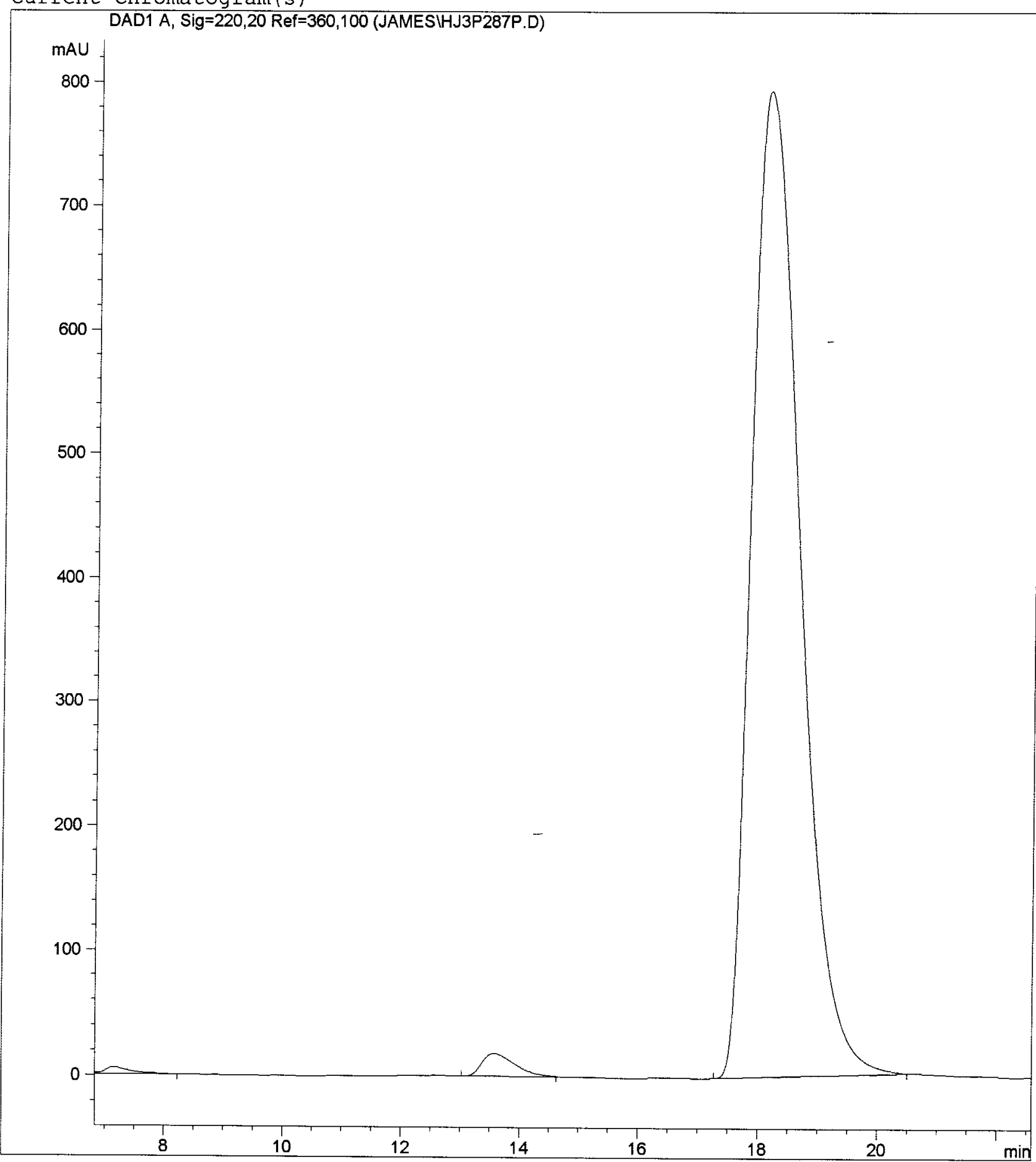


Print of window 38: Current Chromatogram(s)

215 iproh-0.7ml

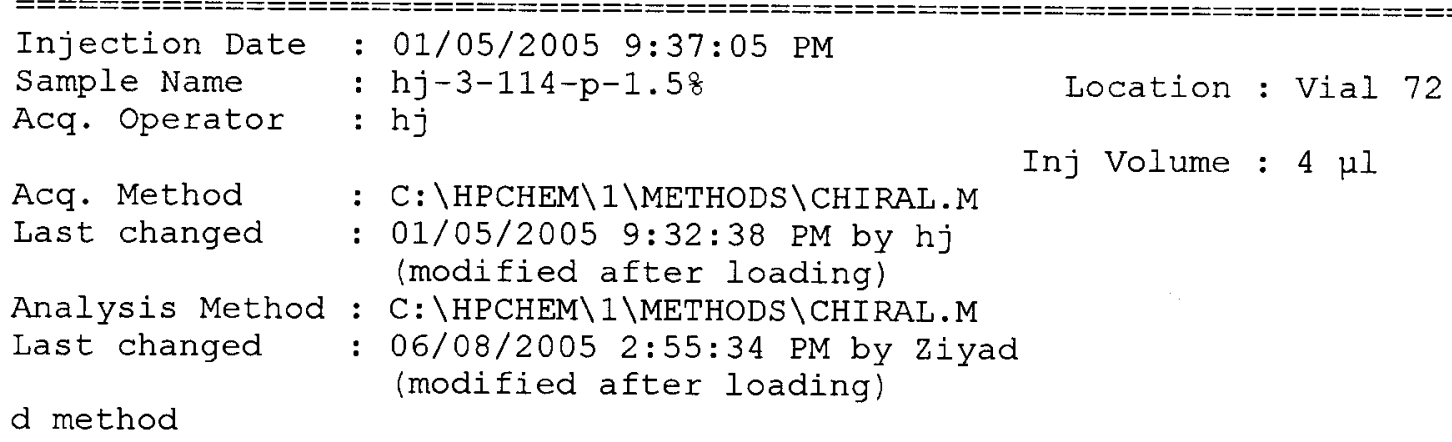<smiles>CCC(O)c1ccccc1C</smiles>

Current Chromatogram (s)

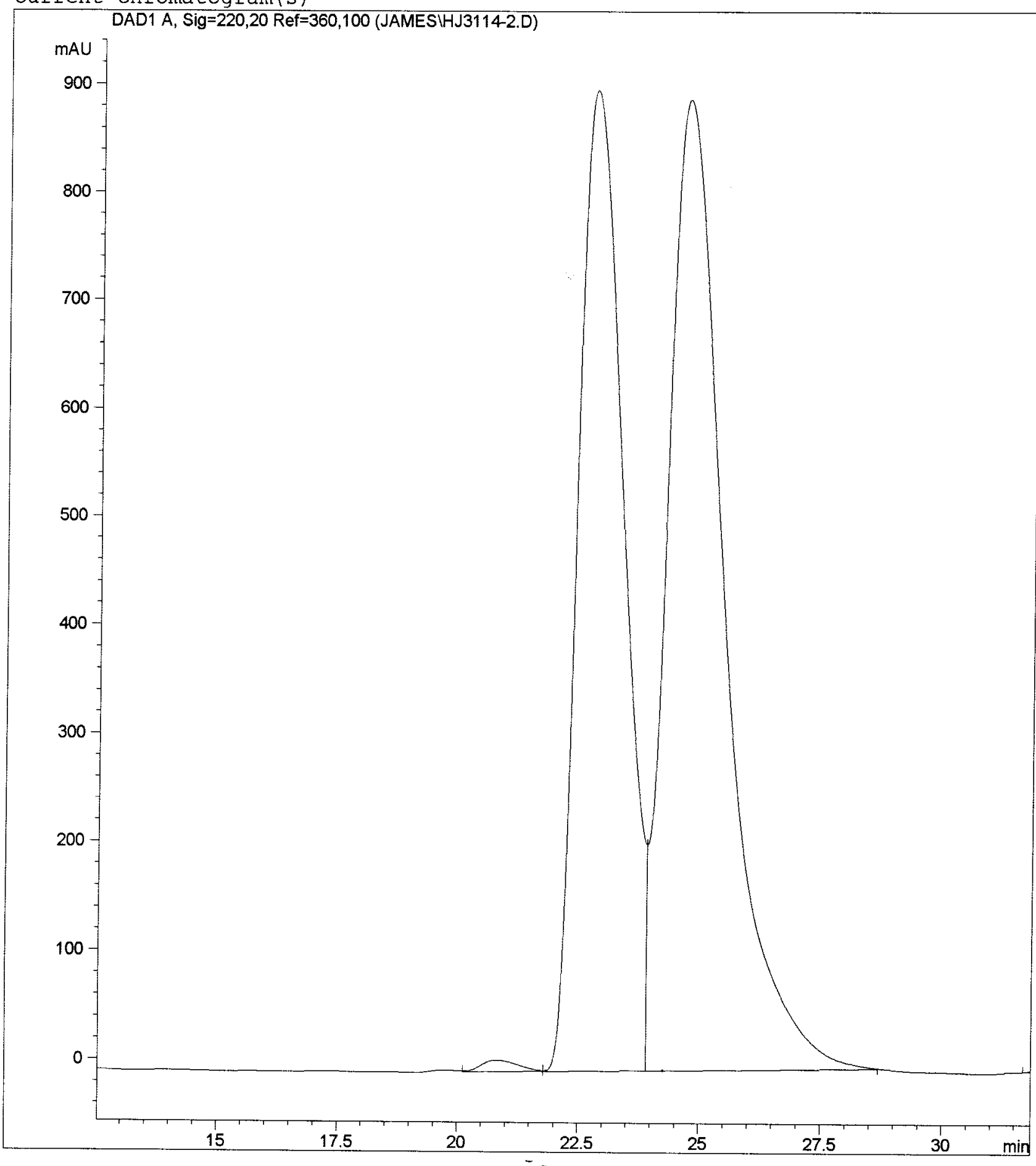


Print of window 38: Current Chromatogram(s)

1.5 \% iproh $-0.7 \mathrm{ml}$

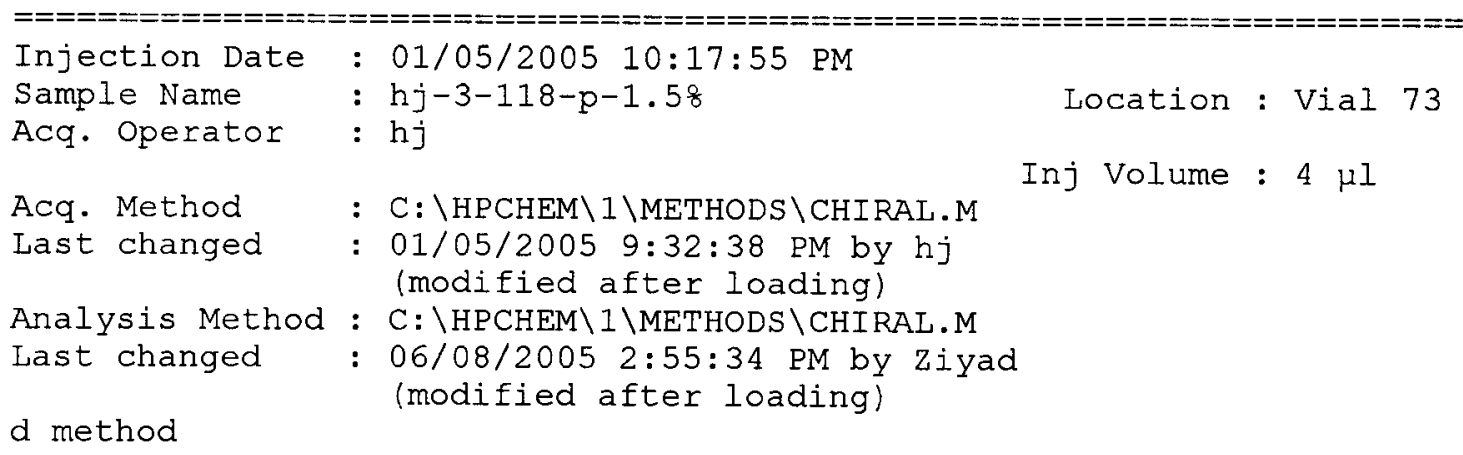

\section{Current Chromatogram (s)}

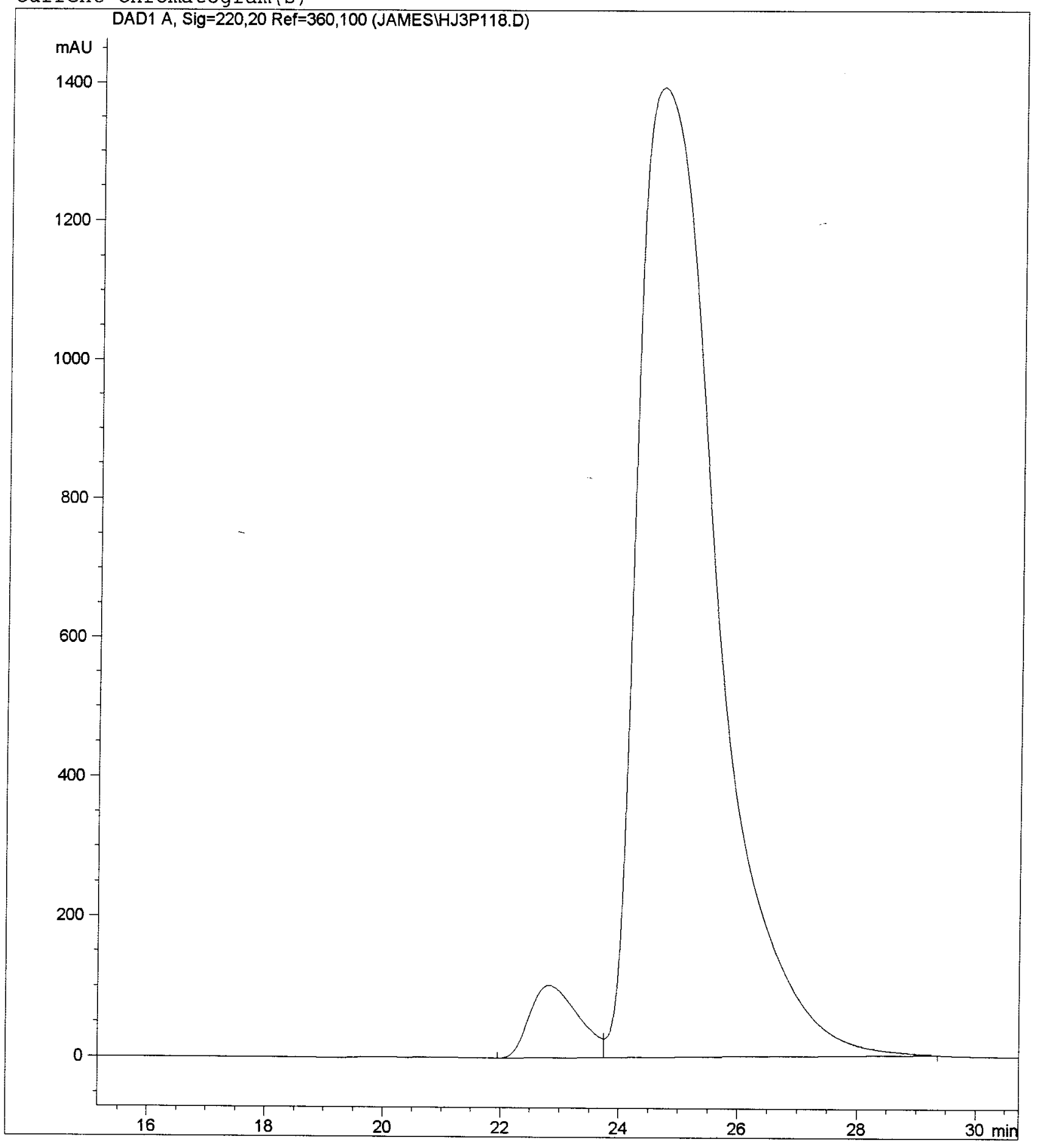




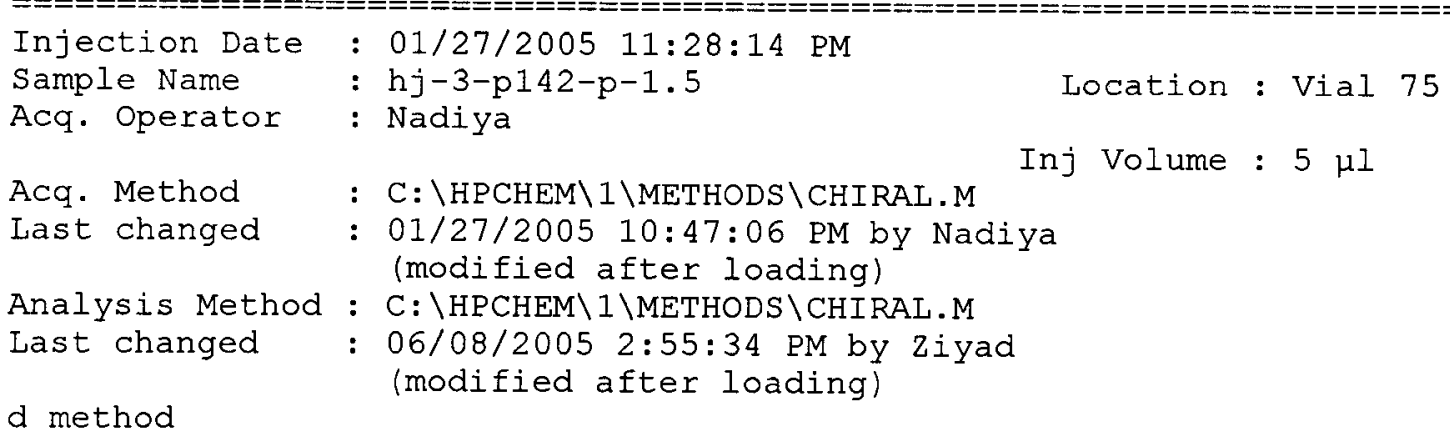<smiles>CCC(O)c1ccc(C)cc1C</smiles>

Current Chromatogram(s)

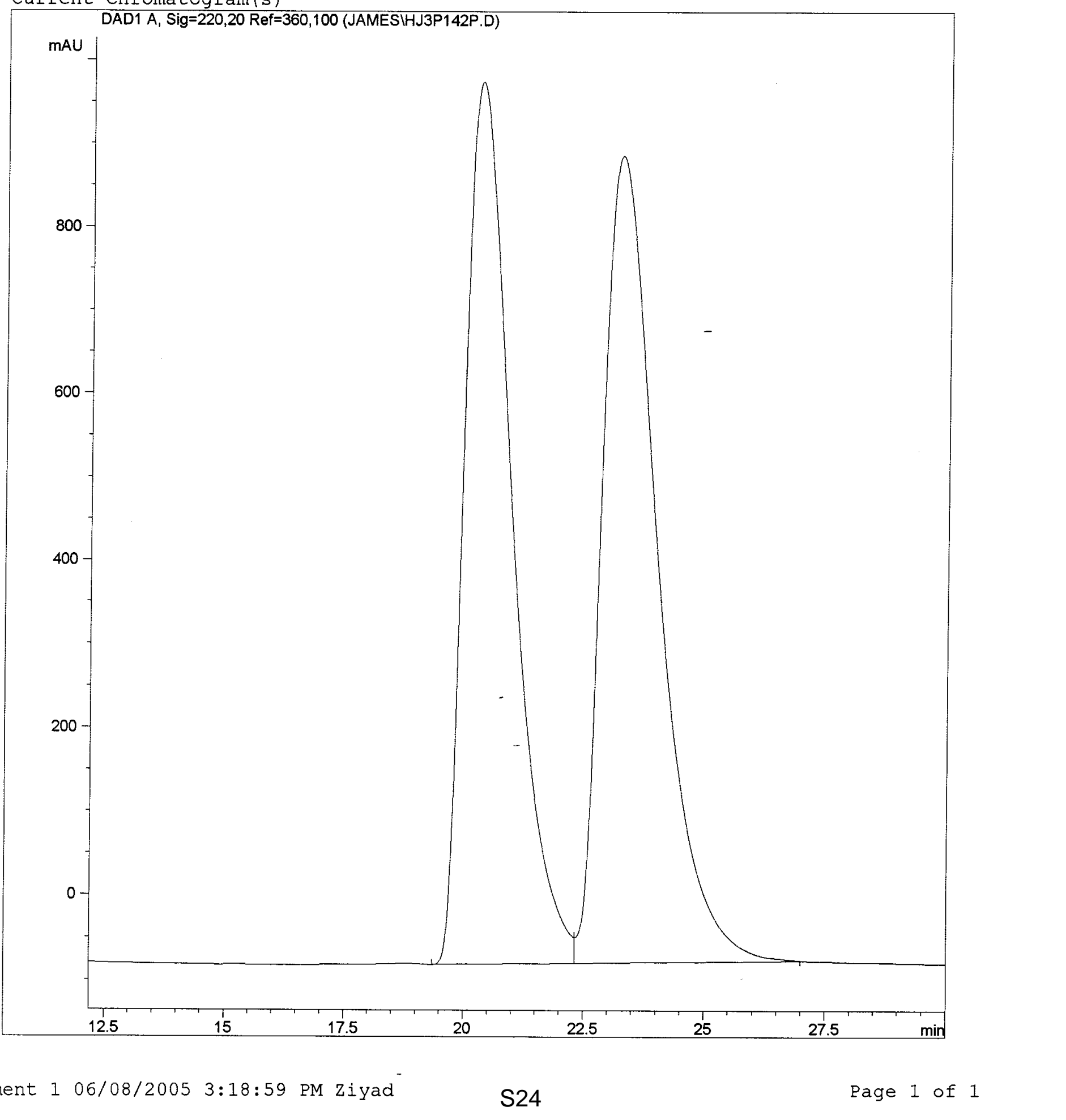


Print of window 38: Current Chromatogram(s)

1.58 iPrOH, $0.75 \mathrm{ml} / \mathrm{min}$

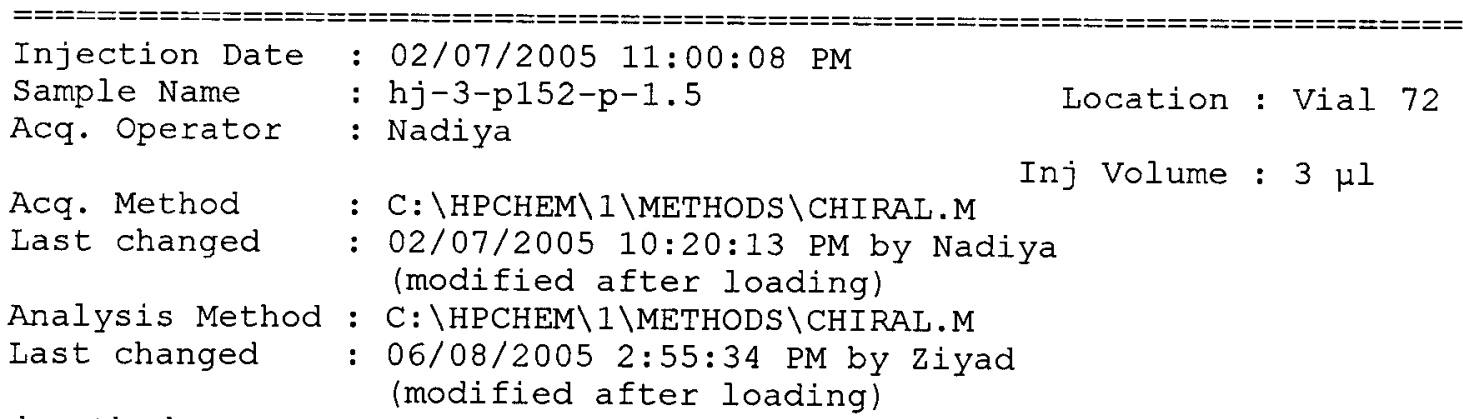

Current Chromatogram(s)

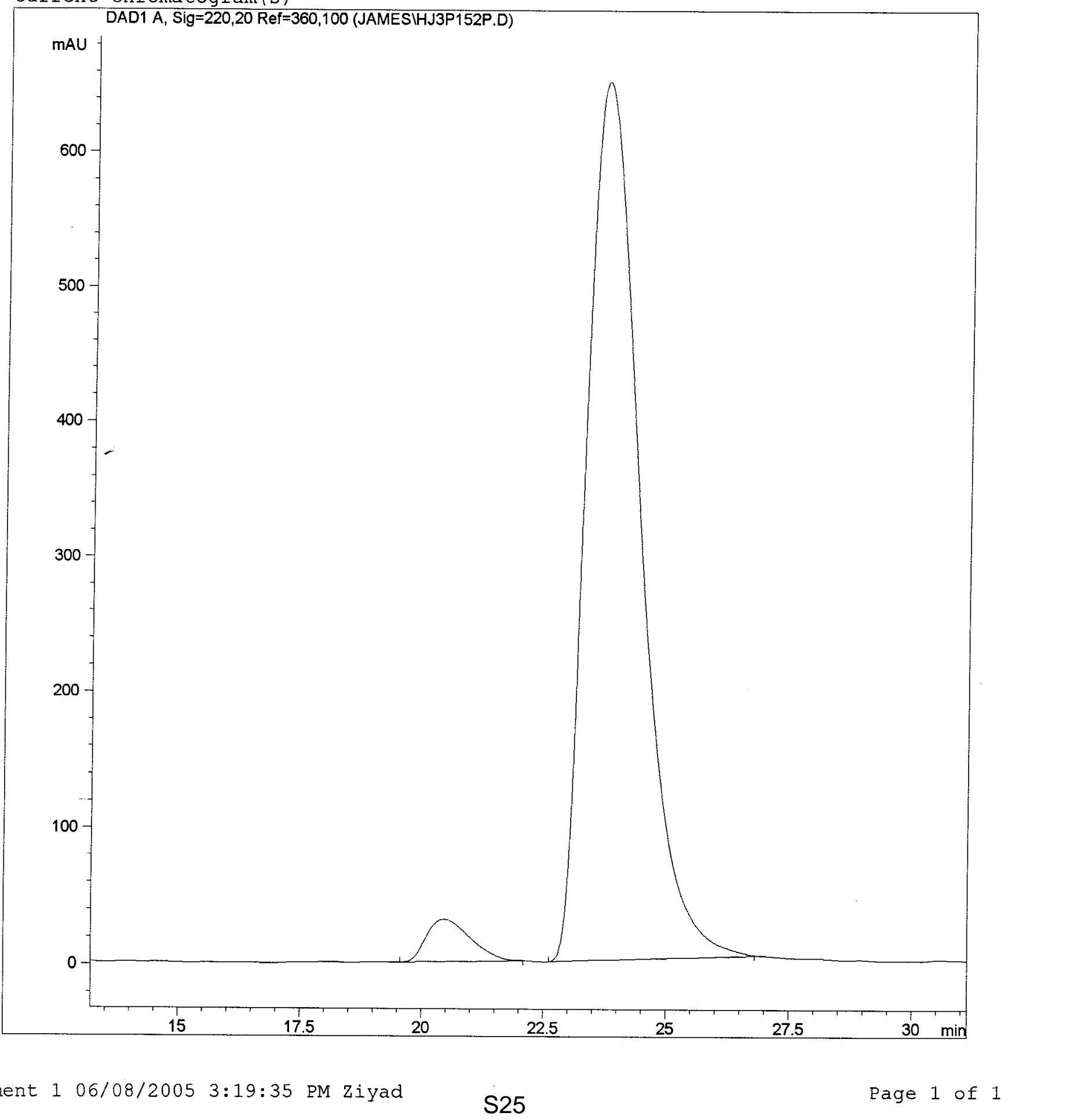



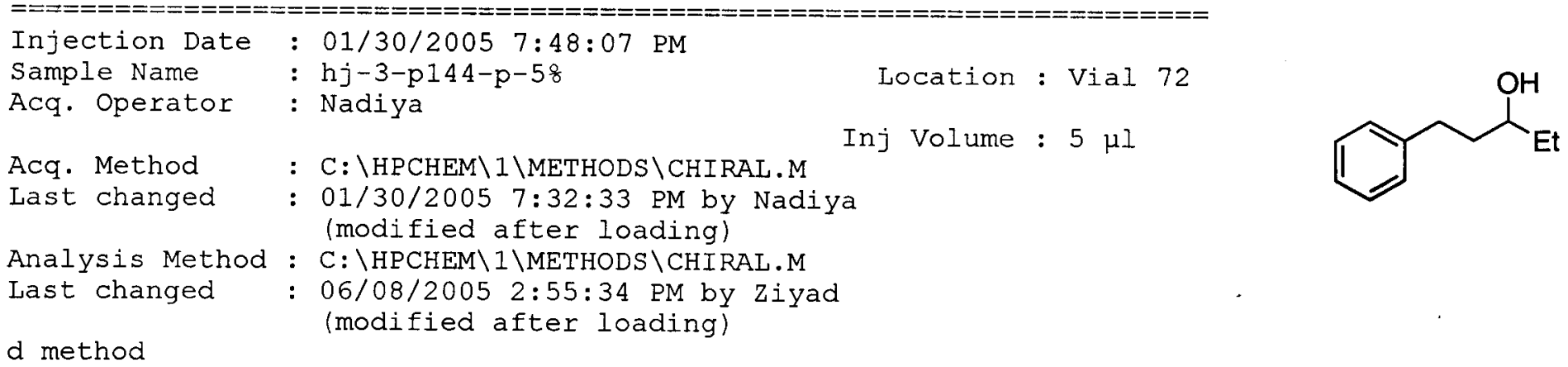

\section{Current Chromatogram(s)}

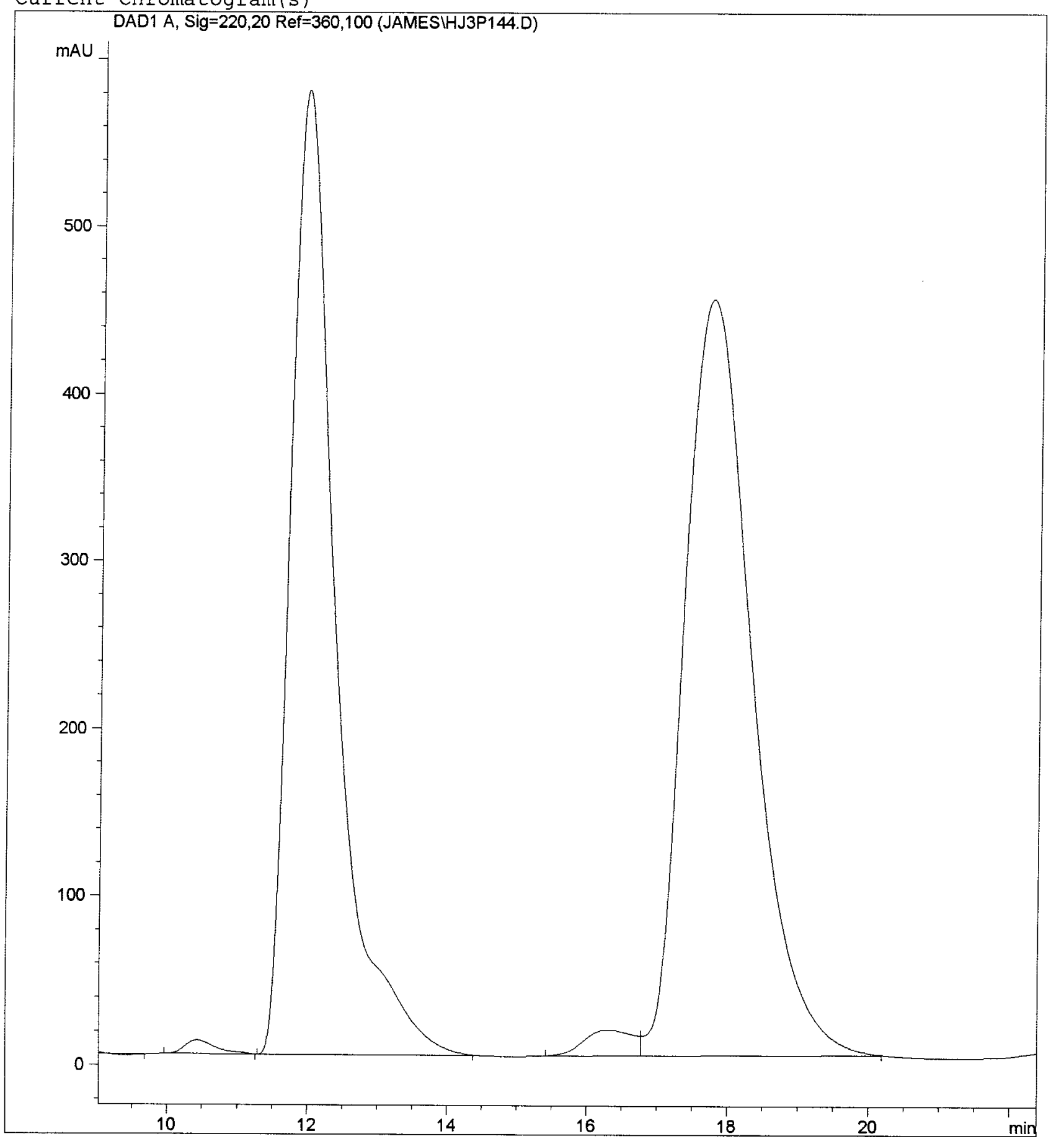


Print of window 38: Current Chromatogram(s)

$\mathrm{Iml} / \mathrm{min} 5$ 응 iPrOH
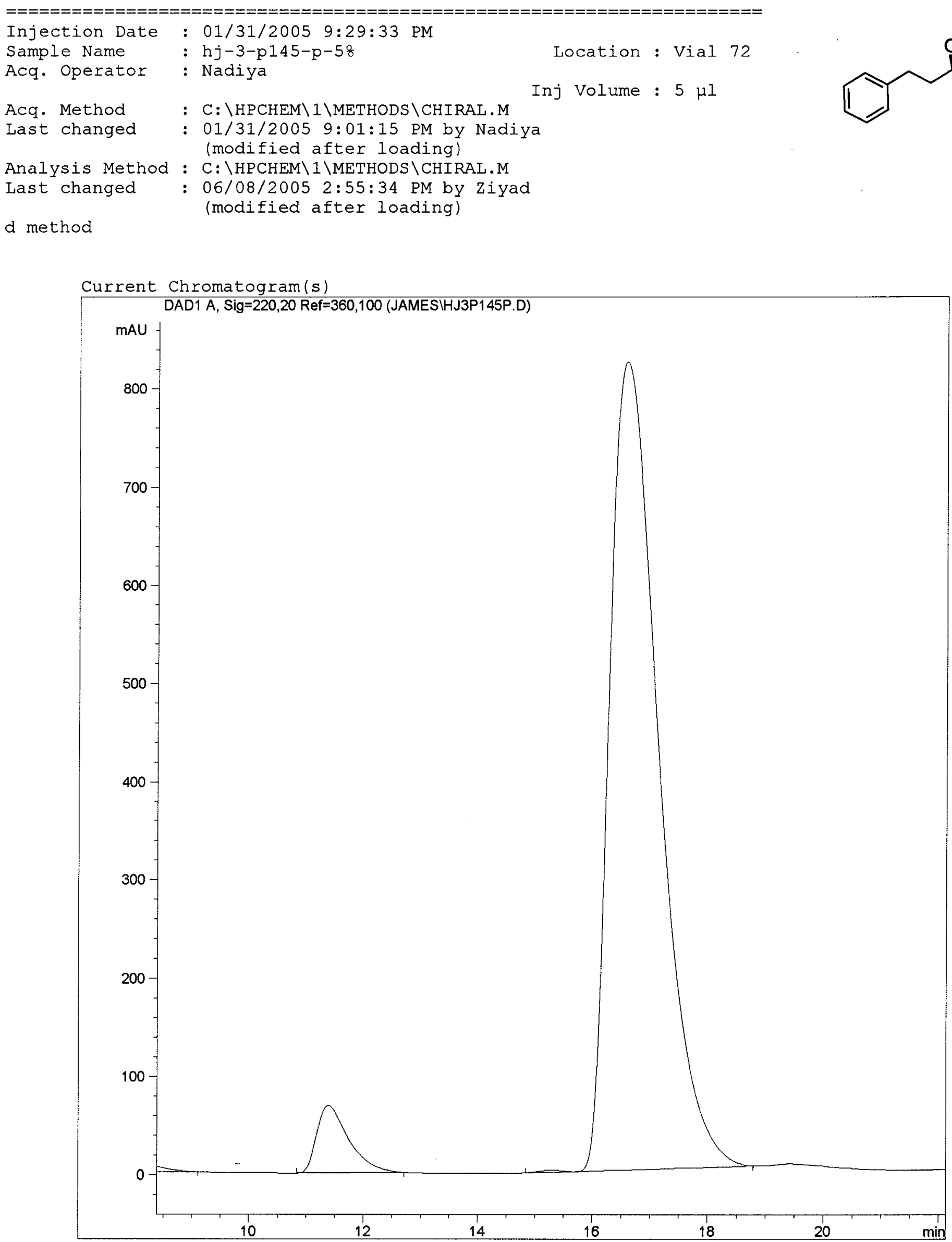
Print of window 38: Current Chromatogram(s)

21.58 iproh $-0.7 \mathrm{ml}$

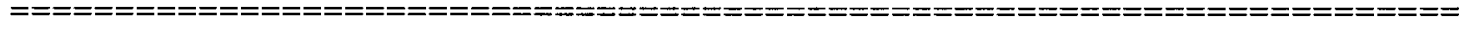

Injection Date : 01/09/2005 3:43:49 PM

Sample Name : hj-3-120-2-1.58

Location : Vial 72

Acq. Operator : hj

Acq. Method : C: \HPCHEM $\backslash 1 \backslash$ METHODS \CHIRAL.M

Inj Volume : $3 \mu l$

Last changed : 01/09/2005 3:40:18 PM by hj

(modified after loading)<smiles>CCC(O)c1ccc(OC)cc1</smiles>

Analysis Method : C: $\backslash$ HPCHEM $\backslash 1 \backslash$ METHODS $\backslash$ CHIRAL.M

Last changed : 06/08/2005 2:55:34 PM by Ziyad

d method (modified after loading)

Current Chromatogram(s)

DAD1 A, Sig $=220,20$ Ref $=360,100$ (JAMESIHJ3120-2.D)

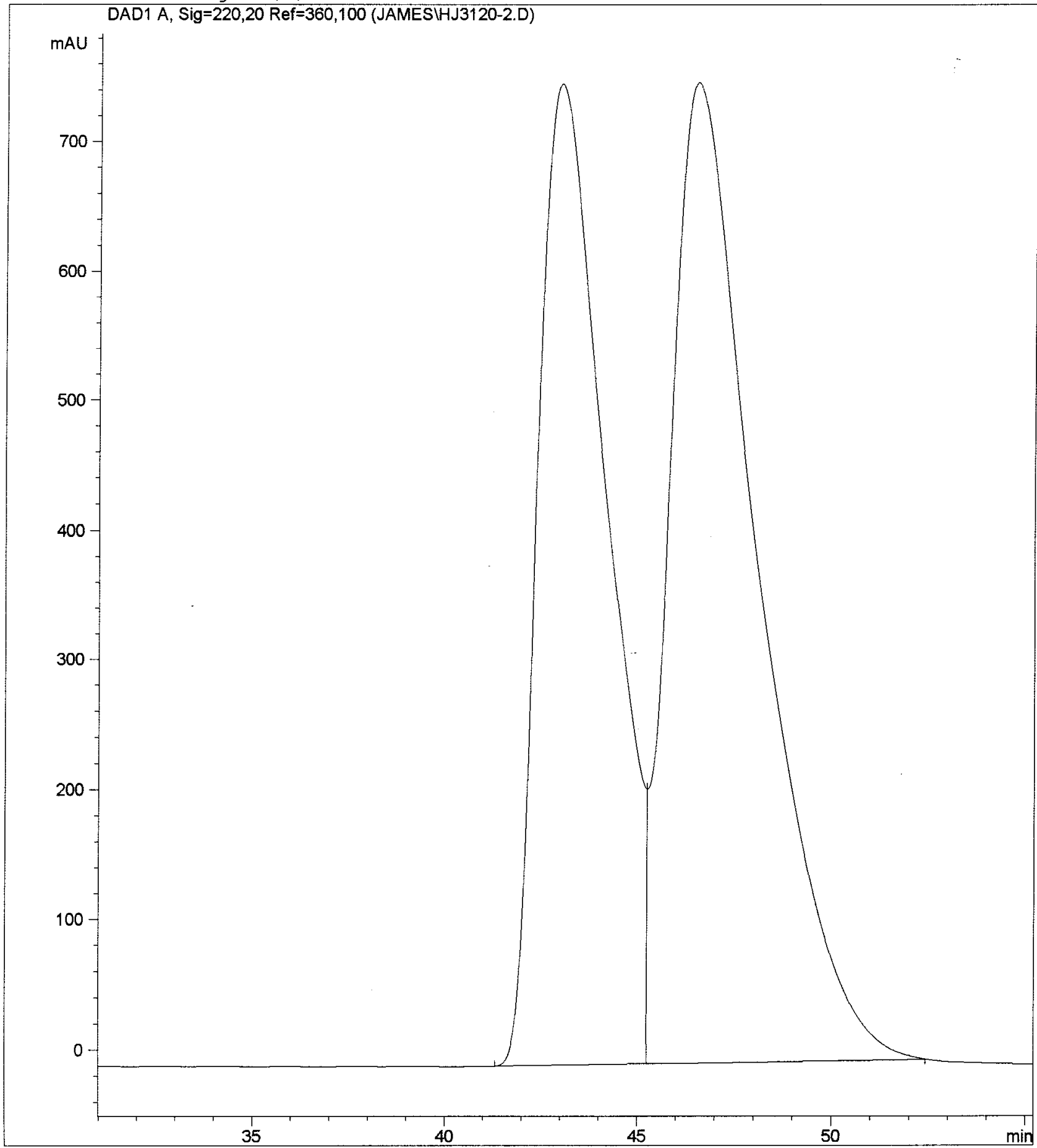


Print of window 38: Current Chromatogram(s)

1.5 o iproh $-0.7 \mathrm{ml}$
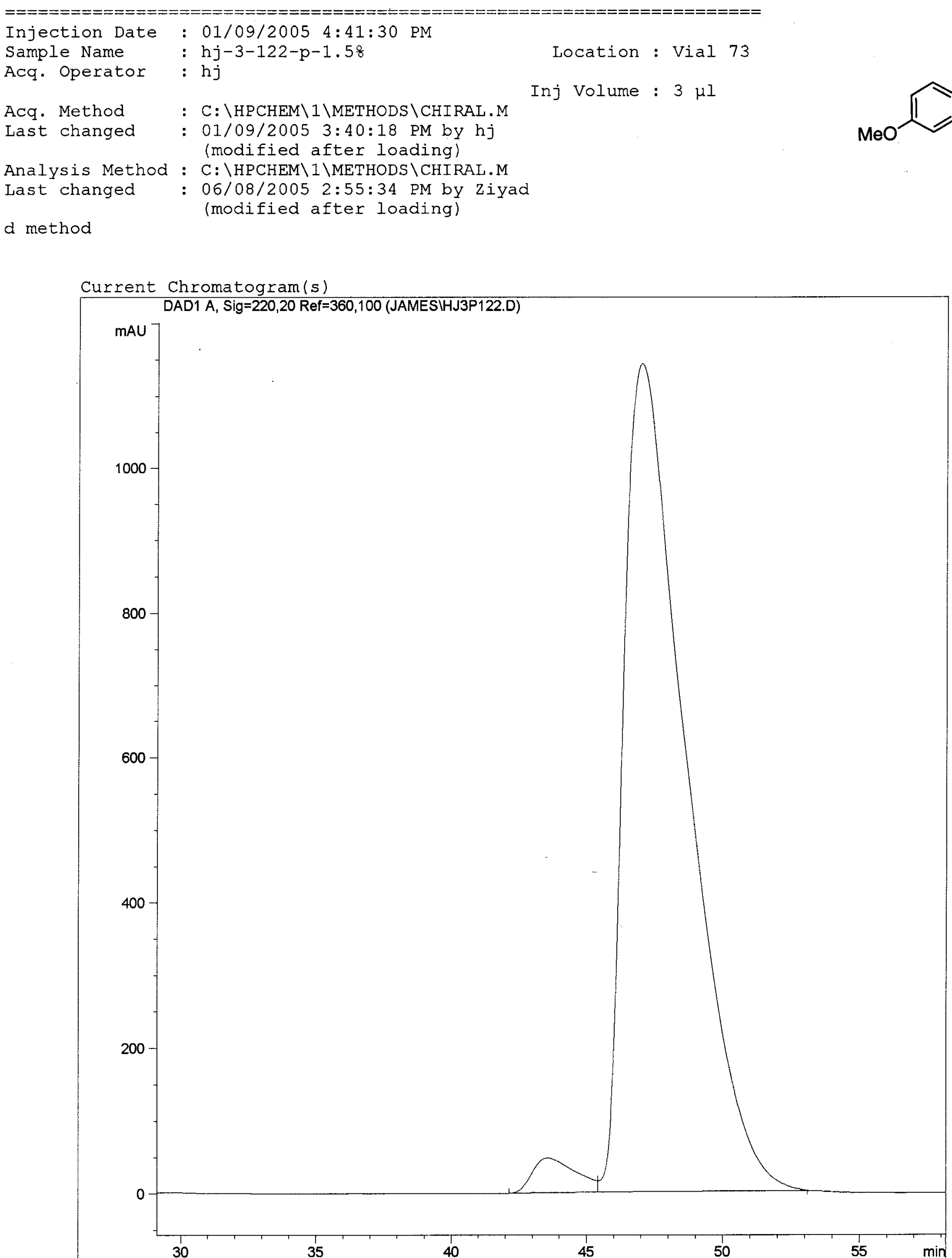